\title{
Monitoring of Noxious Protozoa for Management of Natural Water Resources
}

\author{
Young Yil Bahk ${ }^{1, \dagger}$, Pyo Yun Cho ${ }^{2, \dagger}$, Sung Kyu Ahn ${ }^{3}$, Sangjung Park', Won Hwa Jheong ${ }^{5}$, Yun-Kyu Park ${ }^{3}$, \\ Ho-Joon Shin ${ }^{6}$, Sang-Seob Lee ${ }^{7}$, Okjae Rhee ${ }^{8}$, Tong-Soo Kim ${ }^{3, *}$ \\ 'Department of Biotechnology, College of Biomedical and Health Sciences, Konkuk University, Chungju 27478, Korea; ${ }^{2}$ Protist Resources Research \\ Division, Nakdonggang National Institute of Biological Resources Sciences, Sangju 37242 Korea; ${ }^{3}$ Department of Tropical Medicine and \\ Parasitology, Inha University School of Medicine, Incheon 22212, Korea; ${ }^{4}$ Water Supply and Sewerage Research Division; ${ }^{5}$ Environmental Health \\ Research Division, National Institute of Environmental Research, Incheon 22689, Korea; ${ }^{6}$ Department of Microbiology, Ajou University School of \\ Medicine, Suwon 16499, Korea; ' Department of Life Science, Kyonggi University, Suwon 16227, Korea; ${ }^{8} D K$ EcoV Environmental Microbiology Lab., \\ Cheonan 31075, Korea
}

\begin{abstract}
Waterborne parasitic protozoa, particularly Giardia lamblia and Cryptosporidium spp., are common causes of diarrhea and gastroenteritis worldwide. The most frequently identified source of infestation is water, and exposure involves either drinking water or recreation in swimming pools or natural bodies of water. In practice, studies on Cryptosporidium oocysts and Giardia cysts in surface water are challenging owing to the low concentrations of these microorganisms because of dilution. In this study, a 3-year monitoring of Cryptosporidium parvum, Giardia lamblia, and Naegleria fowleri was conducted from August 2014 to June 2016 at 5 surface water sites including 2 lakes, 1 river, and 2 water intake plants. A total of 50 water samples of $40 \mathrm{~L}$ were examined. Cryptosporidium oocysts were detected in $22 \%$ of samples and Giardia cysts in $32 \%$. Water at the 5 sampling sites was all contaminated with Cryptosporidium oocysts (0-36/L), Giardia cysts (039/L), or both. The geometric mean concentrations of Cryptosporidium and Giardia were 1.14 oocysts/L and $4.62 \mathrm{cysts} / \mathrm{L}$, respectively. Thus, effective monitoring plans must take into account the spatial and temporal parameters of contamination because they affect the prevalence and distribution of these protozoan cysts in local water resources.
\end{abstract}

Key words: Cryptosporidium parvum, Giardia lamblia, Naegleria fowleri, noxious protozoa, catchment scale investigation

Infectious parasitic diseases, once considered eliminated from the list of public health issues, remain a major cause of severe illnesses worldwide. Epidemiological parameters such as dramatic changes in technology, travel, and the environment, particularly climate change, together with the diminished effectiveness of certain measures of disease control, have propelled our society into a new era of parasitoses. The spectrum of infectious parasitoses is once again expanding. During diagnosis and treatment, however, most clinicians disregard protozoan infections in diarrheal patients and instead focus on pathogenic viruses and bacteria. Waterborne protozoan diseases have become an unarguable global public health problem and are major factors in epidemic and endemic diseases [1]. Waterborne outbreaks of cryptosporidiosis and giar-

- Received 21 November 2017, revised 12 March 2018, accepted 19 March 2018.

*Corresponding author (tongsookim@inha.ac.kr)

${ }^{\dagger}$ These authors contributed equally to this work.

(c) 2018, Korean Society for Parasitology and Tropical Medicine

This is an Open Access article distributed under the terms of the Creative Commons Attribution Non-Commercial License (http://creativecommons.org/licenses/by-nc/4.0) which permits unrestricted non-commercial use, distribution, and reproduction in any medium, provided the original work is properly cited. diasis have been reported in several countries [6-8]. At present, infections caused by Giardia lamblia account for $2.8 \times 10^{8}$ cases of diarrhea annually [9]. One of the major outbreaks occurred in 1993 as a waterborne gastroenteritis epidemic in Milwaukee, Wisconsin, which was attributed to the presence of Cryptosporidium parvum oocysts in drinking water supplied by a local water treatment plant $[2,3]$. This protozoan is one of the main causes of 4 billion cases of diarrhea, which is one of the 5 most common disease factors in death, causes $21 \%$ of deaths in children under 5 years of age, and is now recognized as a major global epidemic [4,5].

The most prevalent waterborne protozoan parasitoses causing diarrhea are cryptosporidiosis and giardiasis. Cryptosporidium and Giardia are protozoa that have environmental stages of the life cycle (oocyst and cyst) that are excreted into the host feces. In Korea, a nationwide survey of protozoan infestation among diarrheal patients was conducted during 2004-2006 [10] and showed that the prevalence of protozoan cysts was 129 per 10,000 individuals, and among pediatric diarrheal patients, C. parvum was often accompanied by a rotavirus (29.5\%). In 
addition, the unknown pathogens responsible for outbreaks in more than $12 \%$ cases of foodborne illnesses reportedly include manifold protozoa [11]. Most of these protozoa use the fecal-oral route of transmission to reach new hosts directly via infested individuals or contaminated fomites or through ingestion of cysts with contaminated food or water [12].

The economic burden of these diseases is considerable. Furthermore, climate change is likely to influence the prevalence of protozoan parasitoses among humans. The opinion of clinical experts is that diseases caused by emerging or resurging protozoa will dramatically increase in prevalence. The impact on noxious protozoa may be the most serious consequence of climate change in the public health domain. Widespread resistance to insecticides and drugs and genetic changes in pathogens are expected to be critical consequences as well. Therefore, Cryptosporidium and Giardia constitute key threats to public health, even in developed countries.

It is important to establish a management strategy based on the results of testing of water for contamination in relevant sources. Here, we report the results on long-term monitoring of noxious protozoa-C. parvum, G. lamblia, and Naegleria fowleri-for establishment of a water security management system.

Cryptosporidium is a protozoan parasite associated with diarrheal illness in most parts of the world and is a frequent cause of travelers' diarrhea. Infestation is mediated by the ingestion of sporulated oocysts transmitted via the fecal-oral route. These oocysts are remarkably resistant to common disinfectants and to routine chlorination of drinking water. Giardia is a binucleated flagellate protozoan that can exist in cyst form for days. It is also a cosmopolitan enteric parasite with a wide host range that includes domestic and wild animals as well as humans. Giardia is a common cause of gastrointestinal diseases and waterborne diarrhea worldwide. This protozoan is transmitted through the ingestion of cysts, and travelers can contract giardiasis in endemic areas. Infestation is commonly asymptomatic, but mild to moderate self-limiting diarrhea occurs in some cases. N. fowleri, known as the "brain-eating amoeba," is a free-living, bacteria-eating amoeba that may be pathogenic. It causes a fulminant brain infection called naegleriasis, also known as primary amoebic meningoencephalitis, and is typically found in warm freshwater bodies such as ponds, lakes, rivers, and hot springs [13].

For all the protozoa analyzed in this study, the most commonly identified nonhuman source of infestation is water: ei- ther drinking water or recreational exposure in swimming pools [14-16]. The objective of the present study was to identify sources of contaminated water for future implementation of short- and long-term control measures. Available studies on these 3 protozoa pertain to their prevalence in hosts and in drinking water rather than in the environment [17-20]. Here, we describe the results of an investigation of the prevalence of C. parvum, G. lamblia, and N. fowleri in surface water resources and highlight the problem of their timely detection.

A catchment scale investigation of the prevalence of these microorganisms was carried out. Water samples were collected every other month: 10 times from August 2014 to June 2016. Five surface water sampling sites were employed: 2 lakes (Soyang lake [K3] in Gangwon-do and Juam lake [K4] in Jeollanam-do), the Geum river (Hyundo bridge [K5] at Shintanjindong in Daejeon), and 2 water intake plants (Guui [K1] on the Han river in Seoul and Mae-ri [K2] on the Nakdong river in Gimhae-si) (Fig. 1).

The water was sampled at the surface at a distance from the shore where the water depth was approximately waist high ( 1 $\mathrm{m})$. Each sample (40 L) was collected at a 3-m distance from

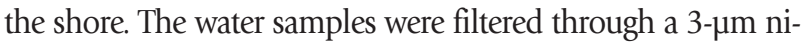
trocellulose membrane in a filter housing with 30 psi pressure.

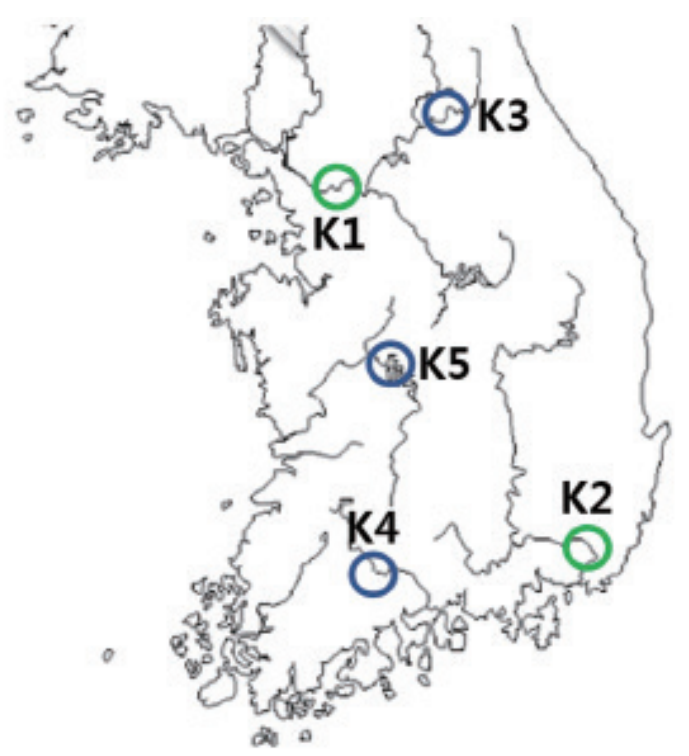

Fig. 1. Locations of the sampling sites in Korea denoting the absence or presence of Cryptosporidium parvum, Giardia lamblia, and/or Naegleria fowleri. K1, Guui water intake plant on Han river in Seoul; K2, Mae-ri water intake plant on Nakdong river in Gimhae; K3, So-yang lake; K4, Juam lake; K5, Geum river in Daejeon. Green circle represents the sampling sites in water intake plant, and blue circle represents the lake and river. 
Each $40 \mathrm{~L}$ sample was processed individually. The nitrocellulose membranes containing protozoa were transported to our laboratory in Incheon and stored at $4^{\circ} \mathrm{C}$ until analysis.

The nitrocellulose membranes were finely chopped in $1 \mathrm{ml}$ of PBS to extract protozoan cysts and/or oocysts from each membrane by vigorous vortexing. The resultant PBS samples were centrifuged at 12,000 $\mathrm{g}$ for $30 \mathrm{~min}$, and the pellet was subjected to a protozoa detection assay. Genomic DNA was extracted directly from the pellets using the QIAamp DNA Stool Mini Kit (Qiagen, Hilden, Germany). Direct fluorescent antibody (DFA) tests and enzyme immunoassays, which detect intact microorganisms and soluble stool antigens, respectively, were performed to detect C. parrum oocysts and G. lamblia cysts [21].

Conventional microscopy, culturing, and antigen detection are limited by relatively low sensitivity and specificity. Polymerase chain reaction (PCR) is a more effective method not only for epidemiological studies but also as a tool for highly sensitive detection of contamination [22]. In practice, microscopic examination is useful, and its application is mandatory for the diagnosis of intestinal parasitoses. Nevertheless, diagnostic sensitivity of microscopic methods is estimated to be 60\% [23]. To identify C. parvum oocysts and G. lamblia cysts, an immunofluorescent assay based on fluorescently labeled mouse monoclonal antibodies was conducted (Crypto Cel IFA test kit and Giardia Cel IFA test kit; Cellabs, Sydney, Australia)
(Fig. 2). PCR was carried out to amplify protozoan DNA within $72 \mathrm{hr}$ after sample collection [24]. The noxious protozoa in water were detected by means of fluorescently labeled antibodies. The test-positive material that reacted with a fluorescent antibody in the assay appeared as greenish oval or spherical particles with bright edges.

The primer sets for PCR amplification were complementary to the Cryptosporidium 18S ribosomal RNA gene sequence (AWA722F: 5'AGTGCTTAAAGCAGGCAACTG-3' AWA1235R: 5'-CGTTAACGGAATTAACC- AGAC-3') or Cryptosporidium oocyst wall protein (COWP) for nested PCR procedures (Cry-15: 5'-GTAGATAATGGAAGAGATTGTG-3', CRY-9: 5'-GGACTGAAATACAGGCATTATCTTG-3', COWPnestF1: 5'-TGTGTTCAATCAGACACAGC-3' and COWPnestR2: 5'-TCTGATTATCCTGGTGGGC-3') [25]. For Giardia, the primer sets were complementary to the Giardia $16 \mathrm{~S}$ ribosomal RNA gene sequence (RH-11: 5'-CATCCGGTCGATC- CTGCC-3', RH-4: 5'AGTCGAACCCTGATTCTCCGCCAGG-3') and the intergenic spacer region (IGS) for nested PCR (AS1: 5'-CGACCGGGACACGATCCTGCC-3', AS2: 5'-AGGACTGCATATCACGGC-3', IGSnestF: 5'-AGAGCAGCCGATCCCCCG-3' and IGSnestR: 5'AATTGGAGGCTGACTGTG-3') [26].

To detect N. fowleri, we performed PCR amplification of the $N$. fowleri Nfa1 gene with the following primer set: Nfa1-F, 5'ATGGCCACTACTATTCCATCACCA-3'; Nfa1-R, 5'-AAGCACTCCCTTGTACTTCAT-3'. Besides, the water samples were analyzed for
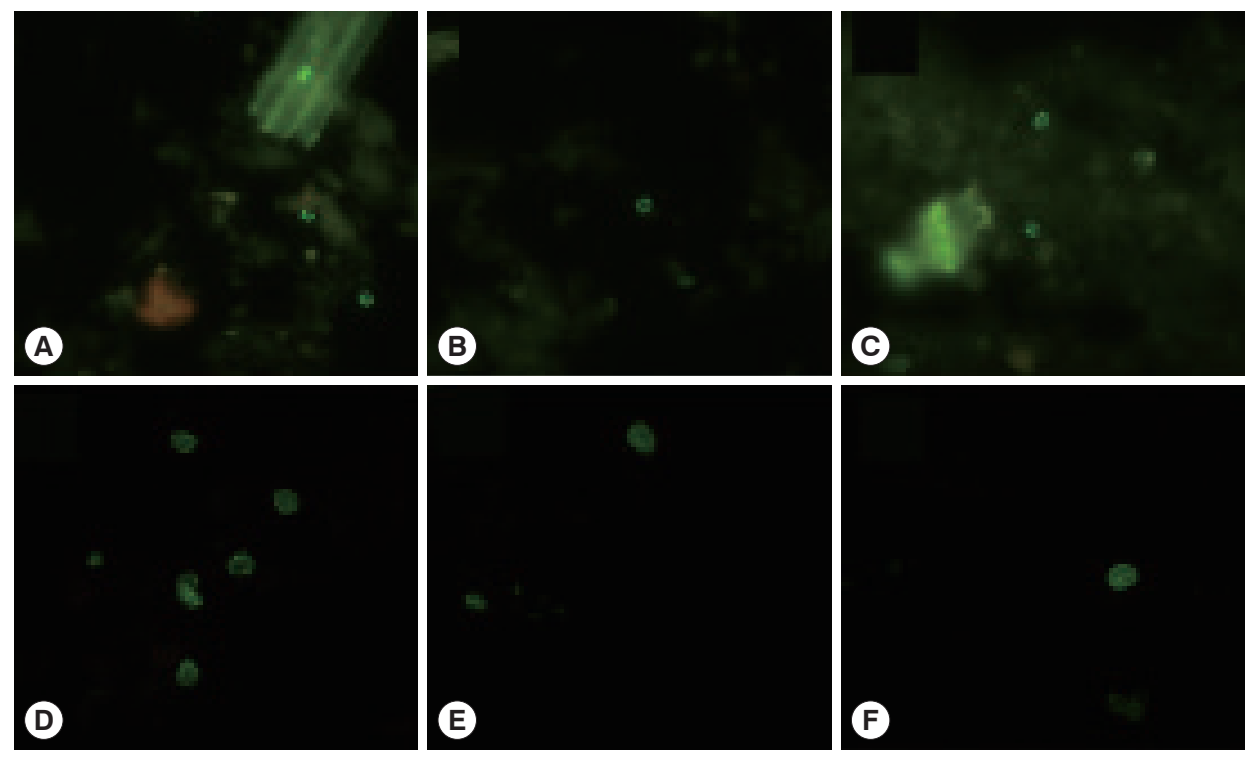

Fig. 2. Photomicrographs of immunofluorescent assay of Cryptosporidium parvum and Giardia lamblia. (A-C), Cryptosporidium parvum. (A) February 2015, So-yang lake. (B) April 2015, Geum river. (C) June 2015, Geum river. (D-F), Giardia lamblia. (D) August 2014, Mae-ri. (E) April 2015, So-yang lake. (F) June 2015, Juam lake. (×1,000 magnifications). 
total culturable protozoa on an Escherichia coli lawn culture plate of a non-nutrient agar medium $(0.01 \%$ yeast extract and $1.5 \%$ agar) [27]. As a result of culturing for 2-4 days, N. fowleri in trophozoite or cyst form was not detected in any water sam- ples by the by direct fluorescence assay (DFA) and PCR.

All water samples from the 5 sites in this study were contaminated with Cryptosporidium oocysts, Giardia cysts, or both at various concentrations (Table 1). The samples obtained in

Table 1. Occurrence of Cryptosporidium and Giardia at 5 water sampling sites (2014-2016)

\begin{tabular}{|c|c|c|c|c|c|}
\hline \multirow{2}{*}{ Date } & \multirow{2}{*}{ Sampling site } & \multicolumn{2}{|c|}{ Cryptosporidium parvum } & \multicolumn{2}{|c|}{ Giardia lamblia } \\
\hline & & DFA test & PCR test & DFA test & PCR test \\
\hline \multirow[t]{5}{*}{ August 2014} & K1: Guui (WIP) & - & - & - & - \\
\hline & K2: Mae-ri (WIP) & - & - & Positive & Positive \\
\hline & K3: So-yang lake & - & - & - & Positive \\
\hline & K4: Juam lake & - & - & Positive & Positive \\
\hline & K5: Geum river & - & - & - & Positive \\
\hline \multirow[t]{5}{*}{ October 2014} & Guui $(\mathrm{WIP})$ & - & - & - & - \\
\hline & Mae-ri (WIP) & - & - & - & - \\
\hline & So-yang lake & - & - & - & - \\
\hline & Juam lake & - & - & - & Positive \\
\hline & Geum river & - & - & - & - \\
\hline \multirow[t]{4}{*}{ December 2014} & Guui (WIP) & - & - & - & - \\
\hline & Mae-ri (WIP) & - & - & - & - \\
\hline & So-yang lake & - & - & - & - \\
\hline & Geum river & - & - & - & - \\
\hline \multirow[t]{5}{*}{ February 2015} & Guui (WIP) & - & - & - & - \\
\hline & Mae-ri (WIP) & - & - & Positive & Positive \\
\hline & So-yang lake & Positive & Positive & Positive & Positive \\
\hline & Juam lake & - & - & - & - \\
\hline & Geum river & - & - & - & - \\
\hline \multirow[t]{5}{*}{ April 2015} & Guui (WIP) & - & - & Positive & Positive \\
\hline & Mae-ri (WIP) & - & - & Positive & Positive \\
\hline & So-yang lake & - & - & Positive & Positive \\
\hline & Juam lake & - & Positive & Positive & Positive \\
\hline & Geum river & Positive & Positive & Positive & Positive \\
\hline \multirow[t]{3}{*}{ June 2015} & Guui (WIP) & - & - & Positive & Positive \\
\hline & Mae-ri (WIP) & - & - & - & Positive \\
\hline & So-yang lake & - & - & - & - \\
\hline \multirow[t]{5}{*}{ December 2015} & Guui (WIP) & - & - & - & - \\
\hline & Mae-ri (WIP) & - & - & - & - \\
\hline & So-yang lake & - & - & - & - \\
\hline & Juam lake & - & - & - & - \\
\hline & Geum river & - & - & - & - \\
\hline \multirow[t]{5}{*}{ February 2016} & Guui (WIP) & - & - & - & - \\
\hline & Mae-ri (WIP) & - & - & - & - \\
\hline & So-yang lake & - & Positive & - & - \\
\hline & Juam lake & - & Positive & - & - \\
\hline & Geum river & - & - & - & - \\
\hline \multirow[t]{5}{*}{ April 2016} & Guui (WIP) & - & - & - & - \\
\hline & Mae-ri (WIP) & - & - & - & - \\
\hline & So-yang lake & - & - & - & - \\
\hline & Juam lake & - & - & - & - \\
\hline & Geum river & - & - & - & - \\
\hline \multirow[t]{5}{*}{ June 2016} & Guui (WIP) & - & - & - & Positive \\
\hline & Mae-ri (WIP) & - & - & - & Positive \\
\hline & So-yang lake & - & - & - & Positive \\
\hline & Juam lake & - & - & - & Positive \\
\hline & Geum river & - & - & - & Positive \\
\hline
\end{tabular}

DFA, direct fluorescent antibody; WIP, water intake plant. 
August and December 2014, December 2015, April 2016, and June 2016 tested negative for Cryptosporidium contamination; however, C. parvum oocysts were detected in some samples collected in February and June 2015 and February 2016. The April 2016 samples from Juam lake and the February 2016 samples from both lakes under study tested positive in the PCR assays. G. lamblia cysts were continuously detected in samples collected between August 2014 and June 2015. Those from So-yang lake and the Geum river in August 2014 and from Lake Juam in October 2014 tested positive in the PCR assay. By contrast, the water samples obtained from the 5 sites between December 2015 and April 2016 tested negative for both C. parrum and G. lamblia according to the DFA analysis, but some tested positive in the PCR analysis. In particular, the samples collected in February 2016 from the 5 sites were testpositive only according to the results of PCR.

For quantitative analysis, Cryptosporidium and Giardia were first identified and enumerated by means of an immunofluorescent reaction in accordance with their sizes and morphological features. Briefly, $40 \mathrm{~L}$ of water collected from each sampling site was transported, filtered on the same day of collection, and concentrated to a final volume of $3 \mathrm{ml}$. Twenty-five microliters of the final filtrate was used in the immunofluorescence microscopy analysis for counting. The results of the recovery of Cryptosporidium and Giardia from $40 \mathrm{~L}$ raw-water samples are presented in Table 2.

The highest concentration of Cryptosporidium (36 oocysts/L), which was identified with the microscopic tools and fluores-

Table 2. Recovery of noxious protozoa (Cryptosporidium and Giardia) from the filtered membrane module

\begin{tabular}{lllc}
\hline Protozoan & Sampling time & Sampling site* & $\begin{array}{c}\text { Oocysts or } \\
\text { cysts/L }\end{array}$ \\
\hline Cryptosporidium & February 2015 & K3: So-yang lake & 36 \\
& April 2015 & K5: Geum river & 9 \\
& June 2015 & K5: Geum river & 12 \\
Giardia & August 2014 & K2: Mae-ri & 39 \\
& December 2014 & K4: Juam lake & 12 \\
& Kebruary 2015 & K2: Juam lake & 15 \\
& & K3: So-yang lake & 24 \\
& K1: Guui & 9 \\
& April 2015 & K2: Mae-ri & 12 \\
& K3: So-yang lake & 21 \\
& K4: Juam lake & 39 \\
& K5: Geum river & 30 \\
& June 2015 & K1: Guui & 9 \\
& K4: Juam lake & 12 \\
\hline
\end{tabular}

cently labeled antibodies as well as PCR, was detected in February 2015 in So-yang lake. The samples from the Geum river obtained in April 2015 and June 2015 contained Cryptosporidium at 9 and 12 oocysts/L, respectively. With respect to Giardia, although the concentrations of cysts in the water samples varied (9-39 cysts/L), the highest concentration of Giardia (39 cysts/L), which was identified by the DFA and PCR analyses, was detected in August 2014, April 2015, and June 2015 in Juam lake, which was the most frequently sampled site (4 of 5 sampling time points; see Table 2). The lowest concentration of confirmed Giardia cysts ( 9 cysts/L) was observed at the sampling sites near the 2 water intake plants (Guui and Mae-ri). Between August 2014 and June 2016, the geometric mean concentrations of Cryptosporidium and Giardia according to DFA and PCR analyses were 1.14 oocysts/L and 4.62 cysts/L, respectively.

Environmental pollution is now considered a global issue. Water contamination, a lack of safe drinking water, and improper disposal of waste residues can lead to serious public health problems. The data from the catchment scale survey in this work will help with identifying and prioritizing the next steps for identifying sources of contamination and elucidating the processes that underpin microbial dissemination. The prevalence of Cryptosporidium, Giardia, and Naegleria at the study sites is crucial because these sites are the principal sources of drinking water for several provinces in Korea.

Researchers and clinicians should be aware of the widely reported 1993 Milwaukee cryptosporidiosis outbreak that affected more than 400,000 individuals $[2,3,6]$. Some time ago, microbiological tests at water treatment and purification plants were reinforced with the rigorous Water Supply and Waterworks Installation Act and Guide for Water Treatment (published in February 2007). Although our results show that each protozoan under study is not always detected in all water sources, the potential risks of cryptosporidiosis and giardiasis must be taken into account. Thus, effective monitoring plans must consider that the spatial and temporal parameters of contamination affect the prevalence and distribution of these 3 protozoans in local water resources.

\section{ACKNOWLEDGMENTS}

This work was supported by a grant from the National Institute of Environmental Research (NIER-2015-01-02-036) funded by the Ministry of Environment (MOE) of the Republic of Korea and the National Research Foundation of Korea (NRF) funded 
by the Korean Government (MEST) (2016R1D1A1B03930804, YYB).

\section{CONFLICT OF INTEREST}

The authors declare that they have no conflicts of interest related to this work.

\section{REFERENCES}

1. Cotruva JA, Durfour A, Rees G, Bartram J, Carr R, Cliver DO, Craun GF, Fayer R, Gannon VPJ. Waterborne Zoonoses: Identification, Causes and Control. London, UK. IWA Publishing. 2004.

2. MacKenzie WR, Hoxie NJ, Proctor ME, Gradus MS, Blair KA, Peterson DE, Kazmierczak JJ, Addiss DG, Fox KR, Rose JB, Davis JP. A massive outbreak in Milwaukee of Cryptosporidium infection transmitted through the public water supply. N Eng J Med 1994; 33: 161-167.

3. MacKenzie WR, Schell WL, Blair KA, Addiss DG, Peterson DE, Hoxie NJ, Kazmierczak JJ, Davis JP. Massive outbreak of waterborne Cryptosporidium infection in Milwaukee, Wisconsin: recurrence of illness and risk of secondary transmission. Clin Infect Dis 1995; 21: 57-62.

4. Kosek M, Bern C, Guerrant R. The global burden of diarrhoeal disease, as estimated from studies published between 1992 and 2000. Bull World Health Organ 2003; 81: 197-204.

5. Baldursson S, Karanis P. Waterborne transmission of protozoan parasites: review of worldwide outbreaks - an update 2004-2010. Water Res 2011; 45: 6603-6614.

6. Fox KR, Lytle DA. Milwaukee's crypto outbreak: investigation and recommendations. J Am Water Works Assoc 1996; 88: 87-94.

7. Kramer MH, Herwaldt BL, Craun GF, Calderon RL, Juranek DD. Waterborne disease: 1993 and 1994. J Am Water Works Assoc 1996; 88: 66-80.

8. Yamamoto N, Urabe K, Takaoka M, Nakazawa K, Gotoh A, Haga M, Fuchigami H, Kimata I, Iseki M. Outbreak of cryptosporidiosis after contamination of the public water supply in Saitama prefecture, Japan, in 1996. J Jpn Assoc Infect Dis 2000; 74: 518-526.

9. Lane S, Lloyd D. Current trends in research into the waterborne parasite Giardia. Crit Rev Microbiol 2002; 28: 123-147.

10. Cheun HI, Cho SH, Lee JH, Lim YY, Jeon JH, Yu JR, Kim TS, Lee WJ, Cho SH, Lee DY, Park MS, Jeong HS, Chen DS, Ji YM, Kwon $\mathrm{MH}$. Infection status of hospitalized diarrheal patients with gastrointestinal protozoa, bacteria, and viruses in the Republic of Korea. Korean J Parasitol 2010; 48: 113-120.

11. Korea Food \& Drug Administration. Outbreak Food Poisoning [Internet]. Available from: http://www.kfda.go.kr/fm.

12. Lanata CF. Studies of food hygiene and diarrhoeal disease. Int J
Environ Health Res 2003; 13 (suppl): 175-183.

13. Kollars TM Jr, Wilhelm WE. The accurence of antibodies to Naegleria species in wild mammals. J Parasitol 1996; 82: 73-77.

14. Hörman A, Korpela H, Sutinen J, Wedel H, Hänninen ML Metaanalysis in assessment of the prevalence and annual incidence of Giardia spp. and Cryptosporidium spp. infections in humans in the Nordic countries. Int J Parasitol 2004; 34: 1337-1346.

15. Marshall MM, Naumovitz D, Ortega Y, Sterling CR. Waterborne protozoan pathogens. Clin Microbiol Rev 1997; 10: 67-85.

16. Nygård K, Schimmer B, Søbstad Ø, Walde A, Tveit I, Langeland N, Hausken T, Aavitsland P. A large community outbreak of waterborne giardiasis-delayed detection in a non-endemic urban area. BMC Public Health 2006; 6: 141.

17. Huh JW, Moon SG, Lim YH. A survey of intestinal protozoan infections among gastroenteritis patients during a 3-year period (2004-2006) in Gyeonggi-do (province), South Korea. Korean J Parasitol 2009; 47: 303-305.

18. Lee MY, Cho EJ, Lee JH, Han SH, Park YS. A survey of Cryptosporidium oocysts in water supplies during a 10-year period (20002009) in Seoul. Korean J Parasitol 2010; 48: 219-224.

19. Lee MY, Cho EJ, Lee JH, Han SH, Park YS. A ten-year survey of Giardia cysts in drinking water supplies of Seoul, Republic of Korea. Korean J Parasitol 2011; 49: 9-15.

20. Cho EJ, Yang JY, Lee ES, Kim SC, Cha SY, Kim ST, Lee MH, Han SH, Park YS. A waterborne outbreak and detection of Cryptosporidium oocysts in drinking water of an older high-rise apartment complex in Seoul. Korean J Parasitol 2013; 51: 461-466.

21. Elgun G, Koltas IS. Investigation of Cryptosporidium spp. antigen by ELISA method in stool specimens obtained from patients with diarrhea. Parasitol Res 2011; 108: 395-397.

22. El-Badry AA, Al-Ali KH, Mahrous ARS. Molecular identification and prevalence of Giardia lamblia and Cryptosporidium in duodenal aspirate in Al-Madinah. J Med Biomed Sci 2010; 1: 47-52.

23. Haque R, Ali LK, Akther S, Petri WA Jr. Comparison of PCR isoenzyme analysis, and antigen detection for diagnosis of Entamoeba histolytica infection. J Clin Microbiol 1998; 36: 449-452.

24. Elsafi SH, Al-Maqati TN, Hussein MI, Adam AA, Hassan MM, Al Zahrani EM. Comparison of microscopy, rapid immunoassay, and molecular techniques for the detection of Giardia lamblia and Cryptosporidium parrum. Parasitol Res 2013; 112: 1641-1646.

25. Yu JR, Lee SU, Park WY. Comparative sensitivity of PCR primer set for detection of Cryptosporidium parrum. Korean J Parasitol 2009; 47: 293-297.

26. Ghosh S, Debnath A, Sil A, De S, Chattopadhyay DJ, Das P. PCR detection of Giardia lamblia in stool: targeting intergenic spacer region of multicopy rRNA gene. Mol Cell Probes 2000; 14: 181189.

27. Kang H, Seong GS, Sohn HJ, Kim JH, Lee SE, Park MY, Lee WJ, Shin HJ. Effective PCR-based detection of Naegleria fowleri from cultured sample and PAM-developed mouse. Eur J Parasitol 2015; 51: 401-408. 